\title{
RESEARCH
}

Open Access

\section{Targeting vulnerable groups of health poverty alleviation in rural China - what is the role of the New Rural Cooperative Medical Scheme for the middle age and elderly population?}

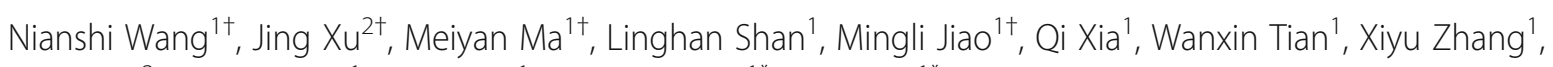
Limin $\mathrm{Liu}^{3}$, Yanhua Hao', Lijun Gao', Qunhong Wu${ }^{1 *}$ and Ye $\mathrm{Li}^{1 *}$ (D)

\begin{abstract}
Background: In light of the health poverty alleviation policy, we explore whether the New Rural Cooperative Medical System (NRCMS) has effectively reduced the economic burden of medical expenses on rural middle-aged and elderly people and other impoverished vulnerable groups. The study aims to provide evidence that can be used to improve the medical insurance system.

Methods: Data were obtained from the 2015 China Health and Retirement Longitudinal Study (CHARLS). The method of calculating the catastrophic health expenditure (CHE) and impoverishment by medical expense (IME) was adopted from the World Health Organization (WHO). The treatment effect model was used to identify the determinants of $\mathrm{CHE}$ for rural middle-aged and elderly people.

Results: The incidence of CHE in rural China for middle-aged and elderly people is $21.8 \%$, and the IME is $8.0 \%$. The households that had enrolled in the NRCMS suffered higher CHE (21.9\%) and IME (8.0\%), than those that had not enrolled (CHE: 20.6\% and IME: 7.7\%). The NRCMS did not provide sufficient economic protection from CHE for households with three or more chronic diseases, inpatients, or households with members aged over 65 years. Key risk factors for the CHE included education levels, households with inpatients, households with members aged over 65 years, and households with disabilities.
\end{abstract}

(Continued on next page)

\footnotetext{
*Correspondence: liye8459@163.com; wuqunhong@163.com

$\mathrm{Ye} \mathrm{Li}$ is the first corresponding author of this study and Qunhong Wu is the second corresponding author of this study

${ }^{+}$Nianshi Wang, Jing Xu, Meiyan Ma and Mingli Jiao contributed equally to this work.

${ }^{1}$ Policy and Management Research Center, School of Health Management, Department of Social Medicine, School of Public Health, Harbin Medical University, No.157 Baojian Road, Nangang District, Harbin 150086, Heilongjiang, China

Full list of author information is available at the end of the article
}

C C The Author(s). 2020 Open Access This article is licensed under a Creative Commons Attribution 4.0 International License, which permits use, sharing, adaptation, distribution and reproduction in any medium or format, as long as you give appropriate credit to the original author(s) and the source, provide a link to the Creative Commons licence, and indicate if changes were made. The images or other third party material in this article are included in the article's Creative Commons licence, unless indicated otherwise in a credit line to the material. If material is not included in the article's Creative Commons licence and your intended use is not permitted by statutory regulation or exceeds the permitted use, you will need to obtain permission directly from the copyright holder. To view a copy of this licence, visit http://creativecommons.org/licenses/by/4.0/. The Creative Commons Public Domain Dedication waiver (http://creativecommons.org/publicdomain/zero/1.0/) applies to the data made available in this article, unless otherwise stated in a credit line to the data. 
(Continued from previous page)

Conclusions: Although the NRCMS has reduced barriers to the usage of household health services by reducing people's out-of-pocket payments, it has not effectively reduced the risk of these households falling into poverty. Our research identifies the characteristics of vulnerable groups that the NRCMS does not provide enough support for, and which puts them at a greater risk of falling into poverty due to health impoverishment.

Keywords: Health poverty alleviation, New rural cooperative medical system, Vulnerable population, Middle-aged and elderly people, China

\section{Introduction}

Poverty is a silent war. According to the World Bank's international poverty line, whose threshold stands at $\$ 1.90$ US dollars a day, $10 \%$ of the total world population in 2015 was poor [1]. Post 2007, 75.9\% of the poor have been mainly concentrated in middle-income countries [2]. Poverty has been a common challenge for all countries. In 2013, one of the 17 goals of sustainable development, proposed in the UN's “The 2030 Agenda for Sustainable Development," was to end all forms of poverty by expanding social protection by 2030, which would further support global sustainability [3].

China's population of rural poor had decreased from 770 million in 1978 to 30.46 million at the end of 2017 , and the total number of people lifted out of poverty in the country was about 740 million [4]. About 19 million people are lifted out of poverty each year. China's contribution alone, to total global poverty reduction, exceeds $70 \%$ [5]. Before the reform and opening-up, China's rural poverty rate was as high as $97 \%$, which means only $3 \%$ of the rural population was not poor. However, post the reform and opening-up in 1978, China's rural poverty rate was reduced to $3.1 \%$ by the end of 2017 [4].

China's exploration of poverty alleviation in rural areas has gone through five stages since 1978 (Fig. 1). In the first stage from 1978 to 1985 , considering the current poverty standards, the rural population living in poverty decreased from 770 million to 660 million, with the incidence of IME (impoverishment by medical expense) falling to $78.3 \%$ [4]. At this stage, the average annual poverty reduction rate in rural areas was $2 \%$. In the second stage, from 1986 to 1993, the proportion of poor people in the total rural population fell from 14.8 to 8.7\% [6]. Through economic development, the isolated, poverty-stricken areas, in central and western regions, were lifted out of poverty, [7] and the annual poverty alleviation rate reached $6.10 \%$.

The third stage, from 1994 to 2000, was when the National Plan for Poverty Reduction was introduced, China's rural poverty alleviation work entered a stage of rapid acceleration. In the 3 years from 1997 to 1999, every year about 8 million people were moved above the poverty line by solving for the lack of food and clothing and through that, alleviating poverty [6]. China's rural areas witnessed the highest poverty alleviation since the 1990s. The resulting rapid economic growth pushed the annual average poverty alleviation rate in the rural areas up to $9.02 \%$. In the fourth stage from 2001 to 2012, poverty-reduction faced new challenges [8]. In 2012, the population of the poor in Chinese rural areas had decreased to 98.99 million, and the incidence of IME had fallen to $10.2 \%$ [4].

In the 2001-2012 period, the economy continued to develop at a relatively fast pace in, but the annual average poverty reduction rate dropped from 9.02 to $7.1 \%$. The trickle-down effect of economic development was not enough to lift the remaining population out of poverty. The marginal diminishing effect of existing antipoverty policies and the changes in the characteristics of the poverty-ridden population, posed great challenges to poverty alleviation that could not be effectively solved by existing strategies [9]. In order to achieve the goal of completely eradicating poverty by 2020 , China's poverty alleviation strategies had to change with the times [10]. Therefore, in the fifth stage, China implemented the strategy of Targeted Poverty Alleviation (TPA) in 2013, which was important to innovate and develop the poverty alleviation methods [11]. Under this policy, the annual average poverty reduction rate increased to $15.97 \%$ during the 2013-2018 period.

However, the long-standing urban-rural dualistic structure, along with the natural resources and social factors that restrict rural development, resulted in a total of 43.4 million people still living in poverty at the end of 2016 [4]. Although the five-guarantee households enjoy the policy assistance provided by the national policies for their food, clothing, housing, medical care and burial, such households are inherently vulnerable to poverty due to the elderly and disabled members [12].At the same time, according to the statistical bulletin issued by the National Bureau of Statistics of China, among the poor people in rural China, the number of people in poverty due to an illness was $44.1 \%$, and those in poverty due to long-term chronic diseases (such as cardiovascular diseases) was $22.8 \%$ [13]. The rural population had a serious economic burden. Impoverishment from medical expenses or returning to poverty due to illness, had become one of the largest factors contributing to the 
poverty of the rural population. It is estimated that the annual growth rate of medical expenses for the elderly in China will increase to $2.2 \%$ in $2010-2030$, which is much higher than that of the United States and other Organization for Economic Cooperation and Development (OECD) countries (0.3-0.5\%) [14]. The number of poor people in rural China is three times more than those in urban areas [15]. At the end of 2017, China's national population reached 1.39 billion, of which the population aged over 60 , reached 240.9 million, accounting for about $17.3 \%$ of the total national population [16]. Moreover, the elderly have always been susceptible to chronic diseases. The economic burden of diseases caused by chronic illnesses accounts for $70 \%$ of the economic burden of all diseases [17]. Older people with chronic diseases must bear the accompanying economic burden of the disease throughout their lives [18]. As the most direct and effective means of health poverty alleviation, the medical insurance system aims to not only protect the health of residents, but also to help them avoid the economic risks associated with the use of medical services [19].

In 2017, the coverage rate of the New Rural Cooperative Medical System (NRCMS) was more than 98\% [20]. However, the disadvantages of the NRCMS have been gradually exposed. While the NRCMS reduced the threshold for the rural population to avail medical services, it also increased the economic burden resulting from diseases. In 2016, the hospitalization reimbursement rate of Urban Employee Medical Insurance was $75 \%$, which was $20 \%$ higher than the NRCMS reimbursement rate [21]. Although the coverage of NRCMS was the highest among the three basic medical insurance programs, it lagged behind the other two programs both in terms of depth and height of coverage [21]. Changes in the demographic structure have led to changes in household demand. Can health poverty alleviation accurately target the most vulnerable segments of the population? Has the NRCMS really alleviated the economic burden of the rural population? Has the overall health poverty alleviation goal been reached? These questions deserve a definitive answer. Therefore, from a multidimensional perspective, we scanned the characteristics of poverty-stricken groups over 45 years of age in rural areas, and identified the key challenges that led to the failure of the NRCMS.

\section{Method}

\section{Data source and sampling method}

This study used the China Health and Retirement Longitudinal Study (CHARLS) database, which is a large-scale interdisciplinary survey project jointly conducted by the National Development Research Institute and the Social Science Research Center of Peking University. In 2015, using multi-stage sampling and Probabilities Proportional to Size (PPS) sampling methods, CHARLS randomly selected 45-year-olds from the survey households that were, in turn, selected from 450 communities in 150 counties of 28 provinces (autonomous regions and municipalities) across China. After data cleaning (eliminating abnormal and incomplete data), 7080 households and a 13,740 people remained and were used to calculate the catastrophic health expenditure (CHE). This database will be openly and freely available to academia 1 year after the survey is completed.

\section{Statistical analysis \\ Catastrophic health expenditure calculation}

The method recommended by the World Health Organization (WHO) was used to calculate the CHE. The key variables in the algorithm included, Out-ofpocket health expenditure (OOP) which is the amount paid by a household member in cash when purchasing health care services, household consumption expenditure (EXP) which is the currency and goods used in all goods and services consumed by the household and a household's capacity to pay (CTP), which is the nonsubsistence spending of a household as a share of total household consumption expenditure.

When OOP exceeds $40 \%$ of the household's ability to pay, the household is considered to have catastrophic health expenditures [22].

\section{Treatment-effect model and instrumental variables}

Since the relationship between medical insurance and catastrophic health care expenditures has a joint causality, and taking into account the literature review, we assumed that householder participation in medical insurance was an endogenous variable [23-27]. To further explore whether it was truly endogenous, we used the DWH (Durbin-Wu-Hausman) test (because data had heteroscedasticity $P=0.000<0.05$ ) which showed $P=0.0493<0.05$, indicating that householder participation in medical insurance was indeed endogenous. In order to address this endogeneity, we applied instrumental variables (IV) with treatment-effect models [28].

The basic idea was to identify an instrumental variable that was related to the endogenous variables (whether the householder was insured), but not related to the residual term of the outcome variable (CHE) [29]. Based on previous literature, the regional medical insurance participation rate and provinces were selected as potential instrumental variables. We further screened for strong instrumental variables through three steps: a) The overidentification test was used to confirm that the variable was exogenous and not related to the residual term of the outcome variable (CHE); b) The F-test was conducted to identify the correlation between instrumental variables 
and endogenous variables (whether the householder was insured); and c) The redundancy test was adopted to check if tool variables were redundant. Finally, the "regional medical insurance participation rate" was identified as the effective instrument variable to enter the treatmenteffect model. (Please see the detailed results in Supplementary Table 1.)

\section{Results}

\section{Sample characteristics}

The total sample comprised 7080 households and 13,740 individuals, the final participation rate of the sample population was $85.8 \%$. (Table 1) $53.1 \%$ of household heads were male, and about $32 \%$ of households had members aged over 65 years. $66.5 \%$, of the total population had primary and junior high school education and more than half (62.5\%) of middle-aged and elderly people had chronic diseases.

\section{The overall prevalence, utilization of health services}

Among households with chronic diseases (Table 2), the prevalence rate of households with three chronic diseases was the highest $(17.2 \%(p=0.02))$. The higher demand for medical services meant higher health service

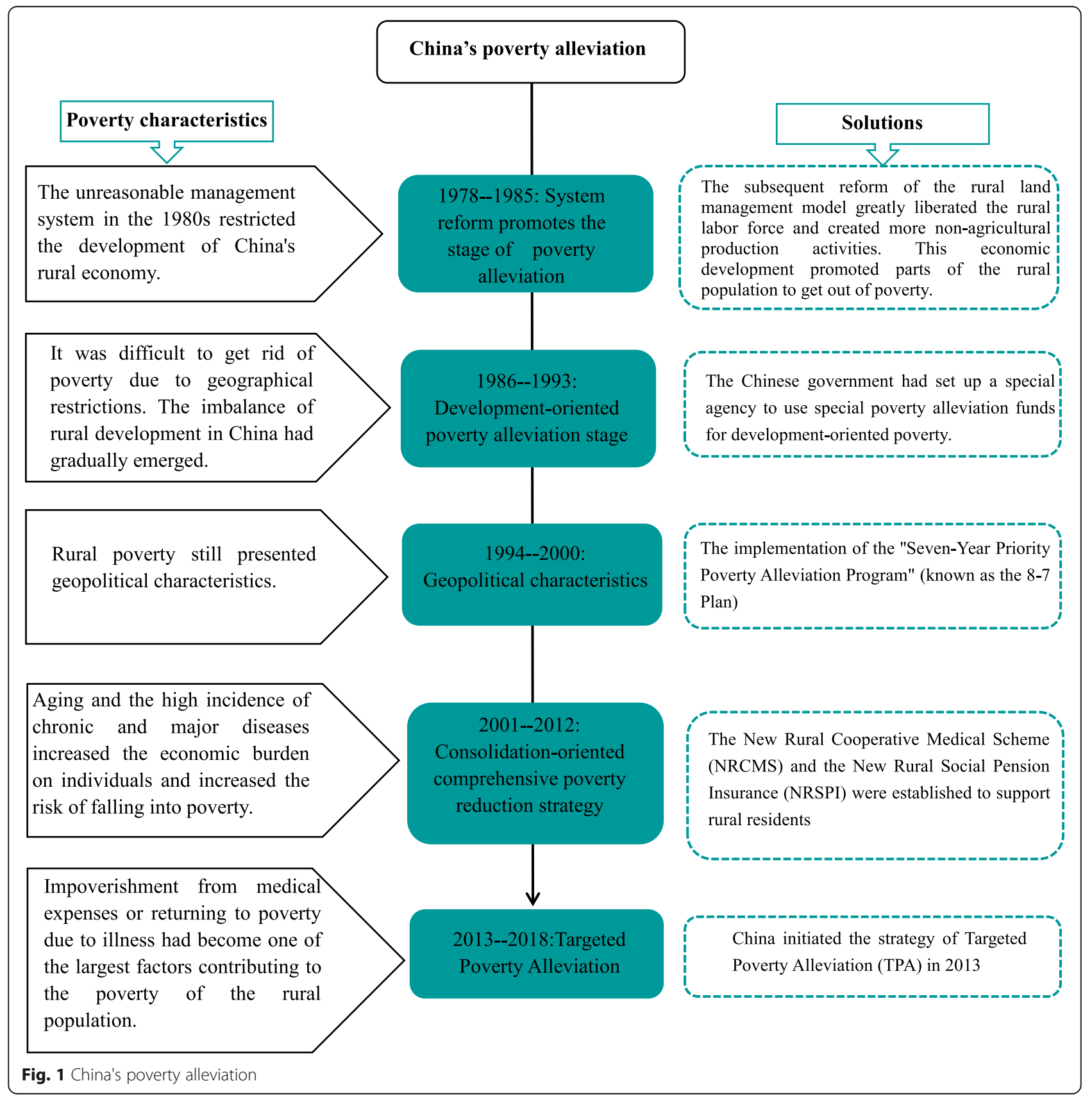


Table 1 Selection and description of variables

\begin{tabular}{|c|c|c|}
\hline Variable & Variable Value & Percentage (\%) \\
\hline \multirow[t]{2}{*}{ Outcome variable } & $0=$ Catastrophic health expenditure did not occur & 78.2 \\
\hline & $1=$ Catastrophic health expenditure occurred & 21.8 \\
\hline \multirow[t]{2}{*}{ Endogenous variable } & $0=$ Uninsured & 14.2 \\
\hline & $1=$ Insured & 85.8 \\
\hline \multirow[t]{2}{*}{ Gender of household head } & $1=$ Male & 53.1 \\
\hline & $2=$ Female & 46.9 \\
\hline \multirow[t]{4}{*}{ Educational level of household head } & $1=$ Illiterate & 24.7 \\
\hline & $2=$ Primary and junior high school & 66.5 \\
\hline & $3=$ High school & 8.6 \\
\hline & $4=$ University and above & 0.1 \\
\hline \multirow[t]{4}{*}{ Career of household head } & $1=$ Agriculture & 54.1 \\
\hline & $2=$ Industry & 20.9 \\
\hline & $3=$ Unemployed & 19.5 \\
\hline & $4=$ Retired & 5.5 \\
\hline \multirow[t]{2}{*}{ Households with members aged over 65 years } & $1=$ Yes & 32.7 \\
\hline & $2=\mathrm{No}$ & 67.3 \\
\hline \multirow[t]{2}{*}{ Households with disabled member } & $0=\mathrm{No}$ & 66.9 \\
\hline & $1=$ Yes & 33.1 \\
\hline \multirow[t]{2}{*}{ Households with inpatients } & $1=$ Yes & 12.5 \\
\hline & $2=\mathrm{No}$ & 87.5 \\
\hline \multirow[t]{4}{*}{ Household members with chronic disease } & $0=0$ species & 37.5 \\
\hline & $1=1$ species & 35.3 \\
\hline & $2=2$ species & 20.0 \\
\hline & $3=3$ species or more & 7.2 \\
\hline \multirow[t]{4}{*}{ Family size } & $1=1$ & 61.8 \\
\hline & $2=2$ & 35.7 \\
\hline & $3=3$ & 2.4 \\
\hline & $4=\geqq 4$ & 0.1 \\
\hline \multirow[t]{3}{*}{ Region } & $1=$ East & 34.7 \\
\hline & $2=$ Central & 42.0 \\
\hline & $3=$ West & 23.3 \\
\hline
\end{tabular}

utilization, with the highest inpatient rate of $15.1 \%$ ( $p=$ 0.005 ) being for households with three chronic diseases. However, their inpatientl reimbursement rate was only $45.8 \%$, nearly $7 \%$ lower than that of households with two chronic diseases. Households with members aged over 65 years had higher health service utilization and high demand for medical services, and a inpatient reimbursement rate of $53.7 \%(p=0.001)$, which was 1.3 times that of households without members aged over 65 years. Households with disabled members also showed the same trend. Meanwhile, the prevalence rate of disease decreased with an increase in the educational level. Compared with households with a high school education, households who were illiterate showed a higher utilization of health services, inpatient rate (14.3\%), and outpatient rate $(20.6 \%)$. Compared with the central region, the health demand and utilization in the western region were both higher, with 20.6\% ( $p=0.000)$ prevalence and $16.4 \%(p=0.000)$ inpatient rate, respectively. Meanwhile, the western region had the highest reimbursement rate of the three regions. The prevalence of uninsured households (15.9\%) was higher than that of insured households (14.8\%); however, both outpatient and inpatient rates were lower for the uninsured households compared with insured households, while the payment ability of the two was almost the same. 
Table 2 Health-care needs and service utilization

\begin{tabular}{|c|c|c|c|c|c|}
\hline Variables & Variable value & Prevalence(\%) & Inpatient rate (\%) & Outpatient rate (\%) & $\begin{array}{l}\text { Inpatient reimbursement } \\
\text { ratio (\%) }\end{array}$ \\
\hline \multirow[t]{2}{*}{ Whether to participate in insurance } & Insured & 14.8 & 13.2 & $20.4^{* *}$ & 45.5 \\
\hline & Uninsured & 15.9 & 12.5 & 16.6 & / \\
\hline \multirow{2}{*}{$\begin{array}{l}\text { Households with members aged } \\
\text { over } 65 \text { years }\end{array}$} & Yes & $16.4^{* *}$ & $15.3^{* *}$ & 21.0 & $53.7^{* *}$ \\
\hline & No & 14.2 & 12.1 & 19.6 & 39.9 \\
\hline \multirow[t]{4}{*}{ Species of chronic diseases } & 0 species & $13.4^{* *}$ & $11.2^{* *}$ & 18.8 & 43.0 \\
\hline & 1 species & 15.60 & 13.8 & 20.8 & 45.1 \\
\hline & 2 species & 16.0 & 14.9 & 21.0 & 52.7 \\
\hline & 3 species & 17.2 & 15.1 & 19.6 & 45.8 \\
\hline \multirow[t]{4}{*}{ Educational level } & Illiterate & 16.0 & 14.3 & 20.6 & $44.5^{* *}$ \\
\hline & $\begin{array}{l}\text { Elementary school and junior } \\
\text { high school }\end{array}$ & 14.8 & 13.1 & 20.2 & 44.6 \\
\hline & High school & 13.0 & 12.1 & 19.2 & 45.2 \\
\hline & University and above & 12.5 & 22.2 & 11.1 & 30.5 \\
\hline \multirow[t]{4}{*}{ Family size } & 1 & 15.1 & 13.4 & 19.7 & 47.9 \\
\hline & 2 & 15.1 & 12.5 & 20.2 & 42.8 \\
\hline & 3 & 13.9 & 14.0 & 22.0 & 43.5 \\
\hline & 4 & / & 25 & 25 & / \\
\hline \multirow[t]{2}{*}{ Disabled } & Yes & $17.2^{* *}$ & $14.9^{* *}$ & 20.5 & 47.8 \\
\hline & No & 13.8 & 12.2 & 19.7 & 45.2 \\
\hline \multirow[t]{2}{*}{ Inpatient } & Yes & $23.8^{* *}$ & $100^{* *}$ & $34.9^{* *}$ & 46.2 \\
\hline & No & 13.9 & / & 17.8 & / \\
\hline \multirow[t]{3}{*}{ Region } & East & $10.6^{* *}$ & $10.7^{* *}$ & $18.0^{* *}$ & 44.3 \\
\hline & Central & 15.6 & 13.2 & 19.9 & 44.6 \\
\hline & West & 20.6 & 16.4 & 23.2 & 50.4 \\
\hline
\end{tabular}

${ }^{*} P<0.05 ;{ }^{* *} P<0.01$

Catastrophic health expenditure (CHE) and impoverished by medical expenses (IME) in different households

The above data (Table 3) showed that the highest incidence of CHE was concentrated in households with members who have three chronic diseases $(38.0 \%(p=$ $0.000))$, inpatients members $(31.0 \%(p=0.000))$, or households with members aged over 65 years $(30.5 \%$ $(p=0.000))$. The NRCMS is an insufficient reimbursement for households that have various chronic diseases, resulting in the highest incidence of $\mathrm{CHE}$, and the households with members aged over 65 years were more at risk of impoverishment by medical expense $(p=$ $0.000)$. The incidence of IME (11.1\%) was $4.7 \%$ higher in the households with members aged over 65 years, than those without members aged over 65 years. The capacity to pay increased with the increase in the education level $(p=0.000)$. The lower capacity to pay of the illiterate group leads to the higher incidence of IME (10.3\%) which is $4.3 \%$ higher than the IME of the households with high school education $(p=0.004)$.
Among the different regions, the incidence of $\mathrm{CHE}$ in the Eastern, central and Western regions exceeded 20\% and the Central region showed the highest $\mathrm{CHE}$ at $22.6 \%$. Surprisingly, the incidence of $\mathrm{CHE}$ for insured households (21.9\%) was higher by $1.3 \%$ than the $\mathrm{CHE}$ for uninsured households, and the incidence of IME was also higher, at $8.0 \%$.

\section{Prevalence rate and utilization of health service demand under different insurance conditions}

Since the incidences of CHE and IME in the insured households were higher than that in the uninsured households, we analyzed the health needs, utilization, and OOP payment of different insured households using different characteristic dimensions and uncovered two results as seen in Table 4.

First, the results showed that, for households with three chronic diseases, inpatient, and below-average household economic level, health insurance increased the residents' use of health services while also increasing 
Table 3 Catastrophic health expenditure and impoverished by medical expenses in different households

\begin{tabular}{|c|c|c|c|c|}
\hline Variables & Variable value & $\begin{array}{l}\text { Out-of-pocket/ } \\
\text { capacity to pay(\%) }\end{array}$ & $\begin{array}{l}\text { Incidence of catastrophic } \\
\text { health expenditures(\%) }\end{array}$ & $\begin{array}{l}\text { Incidence of impoverishment } \\
\text { by medical expense(\%) }\end{array}$ \\
\hline \multirow[t]{2}{*}{ Participate in insurance } & Insured & 19.0 & 21.9 & 8.0 \\
\hline & Uninsured & 19.9 & 20.6 & 7.7 \\
\hline \multirow{2}{*}{$\begin{array}{l}\text { Households with members } \\
\text { aged over } 65 \text { years }\end{array}$} & Yes & $25.9^{* *}$ & $30.5^{* *}$ & $11.1^{* *}$ \\
\hline & No & 16.9 & 17.6 & 6.4 \\
\hline \multirow[t]{4}{*}{ Species of chronic diseases } & 0 species & $15.7^{* *}$ & $16.1^{* *}$ & $5.6^{* *}$ \\
\hline & 1 species & 19.3 & 21.7 & 7.6 \\
\hline & 2 species & 23.2 & 26.5 & 10.6 \\
\hline & 3 species & 34.1 & 38.0 & 14.8 \\
\hline \multirow[t]{4}{*}{ Educational level } & Illiterate & $21.5^{* *}$ & $26.2^{* *}$ & $10.3^{* *}$ \\
\hline & $\begin{array}{l}\text { Elementary school and } \\
\text { junior high school }\end{array}$ & 20.3 & 21.6 & 7.7 \\
\hline & High school & 14.9 & 17.0 & 6.0 \\
\hline & University and above & 5.6 & 0.0 & 0.0 \\
\hline \multirow[t]{4}{*}{ Family size } & 1 & $23.0^{*}$ & $24.6^{* *}$ & $9.0^{* *}$ \\
\hline & 2 & 15.3 & 17.1 & 6.3 \\
\hline & 3 & 16.1 & 16.5 & 6.1 \\
\hline & 4 & 38.7 & 25 & / \\
\hline \multirow[t]{2}{*}{ Disabled } & Yes & $26.0^{* *}$ & $27.3^{* *}$ & $10.2^{* *}$ \\
\hline & No & 16.7 & 19.0 & 6.9 \\
\hline \multirow[t]{2}{*}{ Inpatient } & Yes & $29.7^{* *}$ & $31.0^{* *}$ & $11.0^{* *}$ \\
\hline & No & 17.6 & 20.4 & 7.6 \\
\hline \multirow[t]{3}{*}{ Region } & East & 17.8 & 20.8 & 7.8 \\
\hline & Central & 20.8 & 22.6 & 8.4 \\
\hline & West & 18.5 & 21.5 & 7.5 \\
\hline
\end{tabular}

${ }^{*} P<0.05 ;{ }^{* *} P<0.01$

the amount of OOP payment. Among households with chronic diseases, the prevalence of the insured households $(15.7-16.9 \%)(p=0.006)$ was lower than that of the uninsured households (16.6-17.6\%). Households with three chronic diseases and who were insured had the highest inpatient rate $(15.6 \%)(p=0.002)$, which was $6.1 \%$ higher than that of households that were uninsured. Although insurance coverage increased the utilization of health services, the OOP payment for insured households with three chronic diseases, was 1.3 times that of the OOP payment for uninsured households. However, in other households with one or two chronic diseases, the OOP payments for insured households were much lower than that of uninsured households. For the households with an average or belowaverage economic level, having insurance significantly improved their utilization of medical services. The medical service utilization rate of outpatients in the poorest insured households $(20.7 \%)$ is $7.8 \%$ higher than that of outpatients in the poorest uninsured households. However, the OOP payment (58.38-216.97 yuan) of insured households was generally higher than that of uninsured households (54.09-192.09 yuan) ( $p=0.000$ ).

Second, for households with disabilities, an education level below primary, and a family size with two members or less, having insurance increased the utilization of health services, but their OOP payment did not increase. Among the households with disabled people, the prevalence of households with insurance $(17.1 \%)(p=0.000)$ was lower than that of households without insurance (17.7\%). Their inpatient and outpatient utilization rates were higher than those of the latter. The outpatient utilization rate $(20.8 \%)$ in particular was $2 \%$ higher than the rate of the uninsured households. Having insurance reduced the threshold of health service utilization and provided corresponding economic protection with the OOP being less than the OOP of uninsured households at 41.57 yuan. It can be seen that, in families with two members or less, being covered by the NRCMS ensured that insured households with lowered health demand had higher utilizations, with the outpatient rate (20.1\%) 3.9\% higher than that of uninsured households. Households with lower educational levels also showed the 
Table 4 Utilization of health service under different insurance conditions

\begin{tabular}{|c|c|c|c|c|c|c|c|c|}
\hline \multirow[b]{2}{*}{ Variables } & \multicolumn{4}{|l|}{ Insured } & \multicolumn{4}{|l|}{ Uninsured } \\
\hline & $\begin{array}{l}\text { Prevalence } \\
\text { rate (\%) }\end{array}$ & $\begin{array}{l}\text { Inpatient } \\
\text { rate (\%) }\end{array}$ & $\begin{array}{l}\text { Outpatient } \\
\text { rate (\%) }\end{array}$ & $\begin{array}{l}\text { Out-of-pocket } \\
\text { (yuan) }\end{array}$ & $\begin{array}{l}\text { Prevalence } \\
\text { rate (\%) }\end{array}$ & $\begin{array}{l}\text { Inpatient } \\
\text { rate (\%) }\end{array}$ & $\begin{array}{l}\text { Outpatient } \\
\text { rate (\%) }\end{array}$ & $\begin{array}{l}\text { Out-of-pocke } \\
\text { (yuan) }\end{array}$ \\
\hline Family size 1 & 14.8 & $13.5^{*}$ & 20.1 & 310.46 & 16.9 & 12.3 & 16.2 & 330.35 \\
\hline Family size 2 & 15 & 12.4 & 20.5 & 332.16 & 16.2 & 13.3 & 17.7 & 421.5 \\
\hline Family size 3 & 14.6 & 14.2 & 22.8 & 343.22 & 8 & 11.8 & 15.7 & 392.24 \\
\hline Family size 4 & / & 33.3 & 33.3 & 138 & / & / & / & 417 \\
\hline $\begin{array}{l}\text { Households with members } \\
\text { aged over } 65 \text { years }\end{array}$ & $16.6^{* *}$ & $15.3^{* *}$ & $21.6^{*}$ & $321.13^{* *}$ & 14.7 & 15.5 & 17.1 & 368.12 \\
\hline $\begin{array}{l}\text { Households without } \\
\text { members aged over } 65 \text { years }\end{array}$ & 14 & 12.2 & 20 & 323.00 & 16.3 & 10.8 & 16.8 & 349.33 \\
\hline Having No chronic disease & 13.11 & 11.1 & 19.1 & 306.69 & 14.8 & 11.7 & 16.2 & 319.49 \\
\hline Having One chronic disease & $15.7^{* *}$ & $14.8^{* *}$ & 21.3 & 322.50 & 16.6 & 13.5 & 17.6 & 342.64 \\
\hline $\begin{array}{l}\text { Having Two chronic } \\
\text { diseases }\end{array}$ & 15.8 & 13.8 & 21.6 & 343.78 & 16.7 & 13.8 & 17.6 & 500.61 \\
\hline Having Three chronic diseases & 16.9 & 15.6 & 20.5 & 409.75 & 17.6 & 9.5 & 11.7 & 310.44 \\
\hline No disability & 13.6 & 12.3 & $20.2^{*}$ & 304.34 & 15 & 11.4 & 15.4 & 352.03 \\
\hline Disability & $17.1^{* *}$ & $14.9^{* *}$ & $20.8^{*}$ & $349.58^{* *}$ & 17.7 & 14.7 & 18.8 & 391.15 \\
\hline Inpatient & $23.4^{* *}$ & $100^{* *}$ & $34.5^{* *}$ & $536.26^{* *}$ & 27.3 & $100^{* *}$ & $38.6^{* *}$ & 467.06 \\
\hline No Inpatient & 13.8 & 0 & 18.3 & 289.03 & 14.7 & 0 & 13.5 & 354.54 \\
\hline Illiteracy & 15.5 & 13.1 & 20.2 & 276.49 & 16 & 17 & 16.5 & 406.03 \\
\hline $\begin{array}{l}\text { Elementary school and } \\
\text { junior high school }\end{array}$ & 14.6 & 13.4 & 20.6 & 317.94 & 16.8 & 10.3 & 16.2 & 356.1 \\
\hline High school & 13.1 & 12.1 & 19.8 & 367.78 & 12.7 & 11.4 & 14.6 & 412.58 \\
\hline University and above & 12.5 & 22.2 & 11.1 & 115.47 & / & / & / & 312.5 \\
\hline The poorest level & 14.6 & 13.3 & 20.7 & $58.38^{* *}$ & 17.6 & 10.8 & 12.9 & $54.09^{* *}$ \\
\hline Sub poverty level & 14.8 & 13.1 & 19.7 & 129.18 & 15.6 & 11.3 & 17.9 & 121.97 \\
\hline General level & 14.5 & 12.4 & 20.7 & 216.97 & 14.9 & 11.5 & 14.3 & 192.09 \\
\hline Richer level & 15.5 & 12.4 & 19.8 & 393.53 & 17.7 & 13 & 17 & 369.3 \\
\hline Most wealthy level & 14.8 & 15.3 & 21.3 & 1131.39 & 13.6 & 17.6 & 22.9 & 1158.42 \\
\hline
\end{tabular}

${ }^{*} P<0.05 ;{ }^{* *} P<0.01$

same trend. Looking at health service utilization, the OOP payment of the illiterate population (276.49 yuan) who had insurance was far lower than the 406.03 yuan OOP payment of uninsured households. Among the wealthiest groups, although the OOP payment of uninsured households was 1158 yuan, higher than that of the insured households, their utilization of health services was also higher. The inpatient rate of the wealthiest and uninsured households was 17.6\%, higher than that of the insured households, which showed that medical expenses increased with the increased availability of health services. Therefore, the choice of going for insurance had little effect on the wealthiest households.

\section{Catastrophic health expenditure (CHE) and impoverished by medical expenses (IME) under different insurance schemes}

Considering different insurance schemes (Fig. 2), except for the sub-poor, no chronic disease and most wealthy level households, regardless of the incidence of CHE or IME, the insured households had higher CHE and IME rates than the uninsured households. The most at-risk households were the insured households with three types of chronic diseases (39.44\%), inpatients (32.64\%), and members aged over 65 years (30.9\%). Among the households with three chronic diseases, the incidence of CHE for those enrolled in medical insurance was $8.58 \%$ higher than the incidence for the uninsured. In households with inpatients, the incidence of CHE for households enrolled in medical insurance was 1.4 times that of the uninsured. In households with members aged over 65 years, the incidence of CHE for households enrolled in medical insurance was $2.82 \%$ higher than the uninsured households

However, in households with members aged over 65 years but without medical insurance, the incidence of CHE was still 1.2 times that of the households 


\section{Catastrophic Health Expenditure and Impoverishment by Medical Expense under different health insurance conditions}

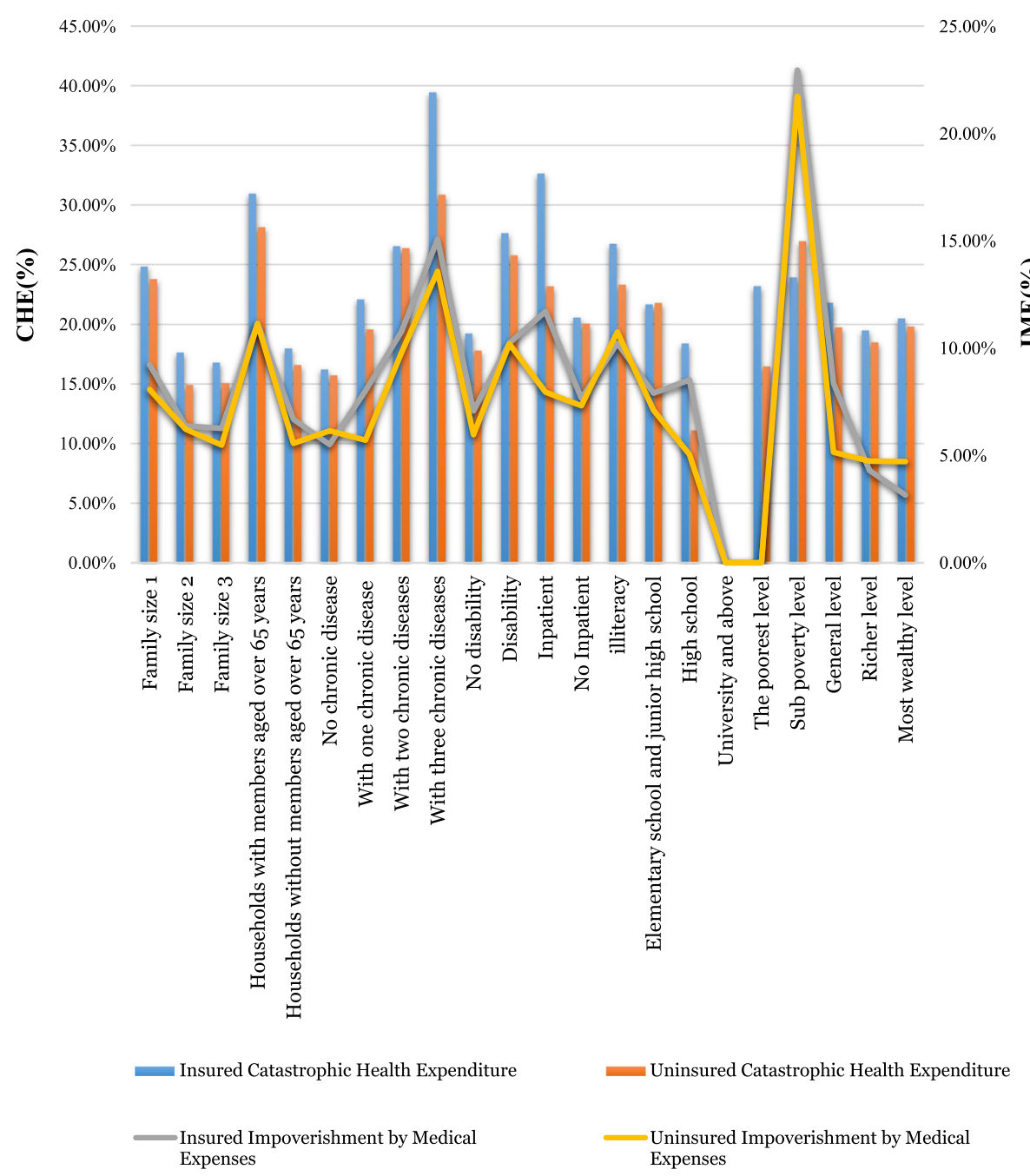

Fig. 2 Catastrophic health expenditures and Impoverishment by Medical Expenses under different health insurance schemes

with two chronic diseases, enrolled in medical insurance. Further, for the sub-poor families, regardless of whether they had medical insurance, the incidence of IME was high $(22.97 \%$ for insured households and $22.74 \%$ for uninsured households). However, it is worth noting that the incidence of CHE in the subpoor households was not the highest (23.93/26.96\%). The second highest incidence of IME was in households with three chronic diseases, $15.08 \%$ in insured households and $13.58 \%$ in uninsured households. Finally, $11.71 \%$ of the insured households with inpatients had an IME 1.4 times higher than that of households with inpatients (7.95\%) without insurance. If the household head had a university level education, the incidence of CHE and IME were both zero.
It can be clearly seen that both the CHE and IME decreased with the increase in the degree of education.

\section{The result of treatment-effect model}

From the results of the treatment-effect model (Table 5), we can see that the education level of the head of the household, households with inpatients, households with members aged over 65 years, disabilities, family size, disease types, as well as whether households were enrolled in insurance, are all determinants of catastrophic household expenditure (CHE) for the middle-aged and elderly people in this study. Among them, households with hospitalization, households with members aged over 65 years, disabled members, and those with chronic disease are the most significant factors impacting CHE. In rural 
Table 5 The result of treatment-effect model

\begin{tabular}{|c|c|c|c|c|}
\hline Variables & Coefficient & SE & Z & $P$ \\
\hline Household head gender & 0.0044 & 0.0137 & 0.32 & 0.749 \\
\hline Household head marital status & -0.0003 & 0.0183 & -0.02 & 0.983 \\
\hline Household revenue logarithm & 0.0124 & 0.0160 & 0.78 & 0.431 \\
\hline Household head educational level & -0.0305 & 0.0124 & -2.45 & 0.015 \\
\hline Inpatient & -0.0722 & 0.0350 & -2.00 & 0.039 \\
\hline Frequency of inpatient & 0.0435 & 0.0217 & 2.01 & 0.045 \\
\hline Region & -0.0119 & 0.0086 & -1.38 & 0.168 \\
\hline Type of jobs & 0.0045 & 0.0032 & 1.40 & 0.160 \\
\hline Households with members aged over 65 years & -0.0802 & 0.0145 & -5.50 & 0.000 \\
\hline Family size & -0.0379 & 0.0120 & -3.15 & 0.002 \\
\hline Type of chronic diseases & 0.0553 & 0.0072 & 7.65 & 0.000 \\
\hline Disabled & 0.0450 & 0.0141 & 3.19 & 0.001 \\
\hline Participate in insurance & 0.1558 & 0.0686 & 2.27 & 0.023 \\
\hline
\end{tabular}

China, income seemed to have no significant association with the incidence of CHE and IME for middle-aged and elderly people.

The CHE decreased by 3.05\% with an increase in education level. The increase in education level had a protective effect on the household. Inpatients in the household increased the incidence of $\mathrm{CHE}$ by $7.22 \%$. Households with members aged over 65 years showed an increased risk of CHE by $8.02 \%$. The larger the family size was, the less likely the family was to incur CHE; the increase in family size reduced the incidence of CHE by $3.79 \%$. Disability increased the incidence of CHE by $4.5 \%$. However, being enrolled in insurance increased the risk of CHE, and the CHE of the insured households increased by $15.58 \%$ when compared with the CHE of uninsured households.

\section{Discussion}

In 2010, more than 808.4 million people incurred catastrophic health expenditures worldwide, representing $11.7 \%$ of the global population [30]. Currently, the overall incidence of $\mathrm{CHE}$ among middle-aged and elderly in rural China is $21.8 \%$, and the IME is $8.0 \%$. Among them, the incidence of CHE in households with three chronic diseases is $38.09 \%$, and the rate of IME is $14.84 \%$, which is higher than the rates in China's urban areas [31] and far exceeds the rate of CHE and IME in other developing countries $[32,33]$. Our research found that the IME rate of insured households was much higher than that of uninsured households, and the highest rate was that of the sub-poor households, at $22.97 \%$. The NRCMS reduced barriers to the use of the health services, thereby decreasing households' OOP payment, affecting households with disabled members, households with elementary and junior high level education, and the households with two or less people. However, in some respects, it was still not efficient in reducing the overall risk of households falling into poverty [34]. We, thus, diagnosed the critical reasons for the failure of the NRCMS:

\section{Inadequate coverage of households with high demand for health services}

First, the reimbursement rate of the NRCMS for the households with high-demand and high-utilization of health services is not adequate, especially for households with three chronic diseases and low education levels. A variety of chronic illnesses and hospitalizations create high demand for medical services, which leads to higher utilization of those medical services and the a weaker ability to pay when compared with other households. Although the NRCMS has lowered the threshold for the utilization of health services, without effective control of medical expenses, it has increased the economic burden on households with three chronic diseases, members aged over 65 years, and inpatients, thus increasing their risk of falling into poverty. This also means that the NRCMS has only increased coverage but has been relatively inadequate in its design for cost reimbursement and benefit packages. Shi's study noted that the increase in NRCMS coverage was accompanied by an increase in utilization of inpatient services. While reimbursement rates also increased at the same time, the total medical expenses and OOP rose more rapidly [35].

NRCMS has achieved better protection for households with one or two chronic diseases, but the protection is still insufficient in the households where there was a superimposition of various chronic diseases. The incidence rate of IME in the superimposed households was 2.64 times higher than in the households without chronic diseases. Combined with the physiological 
vulnerability of the middle-aged and the elderly and the risk of multiple chronic diseases, the insufficient tilt system design of NRCMS has increased the risk of these vulnerable groups to CHE. As a study showed, households with older members and those with chronic illnesses face an increase in demand for the health care system and health expenditures [36]. Moreover, studies had also shown that households with such inadequate protection are more likely to be dragged into poverty due to high expenditures on health care $[37,38]$.

To truly provide economic protection via the NRCMS for rural middle-aged and elderly people in China, it is necessary to extend the policy coverage to chronic diseases, hospitalized patients, and high-risk households with members aged over 65 years, by increasing the reimbursement rate and expanding the coverage of benefit packages. The benefit packages should not only consider direct medical expenses but also the compensation for indirect medical expenses such as time loss due to longterm care required for chronic diseases.

\section{Insufficient inclination towards low socio-economic households}

Secondly, the design of the NRCMS is not inclined toward the lower socio-economic groups, which is one of the reasons for the impoverishment of the disabled or illiterate households, who have a lower capacity to pay. With the increase in education level, the households' capacity to pay also improves, leading to a lower incidence of CHE and IME. There was no CHE and IME observed in households with an educational level of university and above. This shows the great protective effect of education on poverty. Our study is largely consistent with previous studies, which indicate that households with lower literacy levels are at greater risk of catastrophic health care expenditures than those with higher literacy levels [32].

Compared to households without disability households, those with disability have a weaker capacity to pay are more likely to incur CHE. Moreover, the incidence of CHE in households with disabilities is higher than that of uninsured households. At least 500 million of the world's 650 million people with disabilities, are the poorest [39]. Disability is a complex situation that affects not only an individual but also their household, and it reduces the income available to individuals and households [40]. Both the risk of IME and CHE decrease as the family size increases. Some households with fewer members are limited in their ability to access quality and effective health resources and social security benefits. A series of studies has confirmed that larger households mean more working members entering the labor market and more income, which in turn reduces the risk of the household falling into poverty.
Once the householder is unemployed, the ability to resist the economic risks of disease will decrease, resulting in IME [37, 41].

\section{Precise identification and targeting of the characteristics of the poor}

Based on our summary of the key reasons of the failure of the NRCMS, it can be seen that that the crux of insurance failures lies in the problem of identifying and targeting the poor. The NRCMS did not accurately identify and assess the characteristics of the poor and incorporate the same into the system design. As an important area under China's precision poverty alleviation, health poverty alleviation constitutes an institutional means to promote health and poverty alleviation through the integration of basic medical insurance, major medical insurance, medical assistance, and bottom-up protection. However, health alleviation only builds on the original definition of poor population and ignores other potentially poverty-stricken people. Measuring poverty based on income seems to be the most common way, but based on the above research, it is found that the rural poor are not the only ones economically disadvantaged. Those with high demand for health services, households with low economic and educational factors, and low risk of mutual aid, can push "un-poor" households to poverty because of the cost of medical care. Accurate targeting of the poor is of considerable significance for the NRCM $\mathrm{S}$ to maximize the effectiveness of health poverty alleviation. While more precise targeting of poor households vulnerable to poverty and the high medical costs associated with multiple chronic disease is needed, we argue that policymakers, who lead process of reforming health insurance, should also focus on increasing reimbursement gradually and ensuring better compensation for chronic diseases.

\section{Conclusions}

Health poverty alleviation is a comprehensive strategy that requires the convergence of different medical systems. A key point is to accurately capture the characteristics of the poor. Our research identified and targeted the characteristics of vulnerable groups using multidimensional analysis to try and provide direction for accurate poverty alleviation.

As the basic medical insurance, the NRCMS must accurately and comprehensively identify the characteristics of the poor in the early stage, comprehensively cover all the vulnerable people who are at risk due to diseases, and minimize the economic burden of the disease in the basic medical insurance stage. This can reduce the risk of people living in poverty due to illness. For those who are in poverty and cannot afford high medical expenses, further in-depth protection is provided through major 
medical insurance and medical assistance. Medical assistance has developed a general framework for identifying the poor, that is, the economically disadvantaged, those with special needs, and the middle-aged and elderly people. However, for middle-aged and elderly people in rural areas above 45 years of age, these high-risks overlap. Thus, medical assistance still lacks a more detailed and accurate definition of poverty. The existing medical security system is only concerned with people with low-income, special hardships, and major diseases. The definition of vulnerable people is only measured from a single economic dimension, but some people in society do not meet the basic conditions for medical assistance. However, this group of people cannot afford to suffer from chronic and major diseases.

Therefore, we must consider not only poor households and households that fall into the "five guarantees," but also focus on households that are at risk of poverty due to age, education level, family size, chronic diseases, disabilities, and hospitalizations. Based on the above research data, illiterate people, households with three chronic diseases, households with members aged over 65 years, inpatients, and households with small family size should be included in the policy of the Chinese rural middle-aged and elderly medical assistance system.

\section{Supplementary information}

Supplementary information accompanies this paper at https://doi.org/10. 1186/s12939-020-01236-x.

Additional file 1: Supplementary Table 1. Result of validity test and correlation test.

\section{Abbreviations}

CHE: Catastrophic Health Expenditure; IME: Impoverishment by Medical Expenses; NRCMS: New Rural Cooperative Medical System; NRSPI: New Rural Social Pension Insurance; TPA: Targeted Poverty Alleviation;

OECD: Organisation for Economic Cooperation and Development; CTP: A household's Capacity To Pay; OOP: Out-Of-Pocket health expenditure; EXP: Household Consumption Expenditure

\section{Acknowledgements}

We acknowledge the outstanding contributions of Nianshi Wang, Jing Xu, Meiyan Ma, and Mingli Jiao, who contributed equally to the first author of this article. Each author contributed to the concept, design, research, data analysis, drafting of the article.

\begin{abstract}
Authors' contributions
NSW, MYM conducted the literature search, planned the study, carried out data collection, performed data analysis and interpretation and drafted the manuscript. YL conducted framework design and helped conceptualize the project and revised the manuscript, LHS,JX and MLJ reviewed the literature search and data analysis, LML and YHH gave critical feedback. QHW, LJG, WXT, QX, XYZ conducted quality control and review of manuscripts. All authors have read and approved the manuscript.
\end{abstract}

\section{Funding}

This work was supported by the National Natural Science Fund (71874045,71403073,71333003,71804036), China Postdoctoral Science Foundation (2016 M590296), Heilongjiang Health and Family Planning Commission Project (2014-427). The funder had no role in the design of the study, collection, analysis, and interpretation of data, or manuscript preparation.

Availability of data and materials

Database available from the CHARLS repository, http://charls.pku.edu.cn.

Ethics approval and consent to participate

Ethics approval and consent to participate is not applicable due to the retrospective nature of this study.

\section{Consent for publication}

All authors agree to publish.

\section{Competing interests}

The authors declare that they have no competing interests.

\section{Author details}

${ }^{1}$ Policy and Management Research Center, School of Health Management, Department of Social Medicine, School of Public Health, Harbin Medical University, No.157 Baojian Road, Nangang District, Harbin 150086 Heilongjiang, China. ${ }^{2}$ Heilongjiang Provincial Hospital, 82 Zhongshan Road, Xiangfang District, Harbin 150086, Heilongjiang, China. ${ }^{3}$ The Second Affiliated Hospital of Harbin Medical University, 246 Xuefu Road, Nangang District, Harbin 150001, Heilongjiang, China.

Received: 6 March 2020 Accepted: 13 July 2020

Published online: 14 September 2020

\section{References}

1. The Word Bank Data. https://data.worldbank.org.cn/indicator/SI.POV. DDAY?locations=1W\&start=1981\&end=2015\&view=chart Accessed 1 Jun 2020.

2. Sumner A. Where do the poor live? World Dev. 2012;40(5). https://doi.org/ 10.1016/j.worlddev.2011.09.007 Accessed 1 Jun 2020

3. United Nations draft outcome document of the United Nations Summit for the adoption of the Post-2015 Development Agenda. 2015. https:// sustainabledevelopment.un.org/sdg1 Accessed 1 Jun 2020.

4. The National Bureau of Statistics of China. The series of economic and socia development achievements in the 40 years of reform and opening up. 2018. http://www.stats.gov.cn/ztjc/ztfx/ggkf40n/201809/t20180903_1620407. html Accessed 1 Jun 2020

5. United Nations (UN). The Millennium Development Goals Report 2015. 2015.

6. Information Office of the State Council, People's Republic of China. White paper on rural poverty alleviation and development in China. http://www. nwccw.gov.cn/2017-04/11/content_155740.htm Accessed 1 Jun 2020.

7. Guo Y, Zhou Y, Liu Y. Targeted poverty alleviation and its practices in rura China: A case study of Fuping county, Hebei Province. J Rural Stud. 2019. https://doi.org/10.1016/j.jurstud.2019.01.007.

8. Zhou Y, Guo Y, Liu Y, Wu W, Li Y. Targeted poverty alleviation and land policy innovation: Some practice and policy implications from China. Land Use Policy. 2018;74:53-65 doi: 101016/jlandusepol201704037. Accessed 1 Jun 2020

9. Liu Y, et al. Regional differentiation characteristics of rural poverty and targeted poverty alleviation strategy in China. Bull Chin Acad Sci. 2016;31(3): 269-72.

10. The State Council Leading Group Office of Poverty Alleviation and Development. Response to recommendation 2117 of the Second Session of the Thirteenth National People's Congress. http://www.cpad.gov.cn/art/201 9/12/10/art 2202 108145.html Accessed 1 Jun 2020

11. The State Council Leading Group Office of Poverty Alleviation and Development. Big data "counts" major achievements in poverty alleviation. http://www.cpad. gov.cn/art/2019/8/13/art_624_101661.html Accessed 1 Jun 2020.

12. General Office of the State Council, State Council Decree No. 456, People's Republic of China.2006. http://www.gov.cn/flfg/2006-01/26/content_172472.htm.

13. The China National Health Council implements a health poverty alleviation project to prevent rural poor from becoming poor due to illness and returning to poverty due to illness. 2017. http://www.nhc.gov.cn/xcs/2017hydt/201703/3 99de486b5e044a89dfed9e8c1ff596e.shtml Accessed 1 Jun 2020.

14. Zeng Y, Li J, Yuan Z, Fang Y. The effect of China's new cooperative medical scheme on health expenditures among the rural elderly. Int J Equity Health 2019 Feb 06;18(1):27. https://doi.org/10.1186/s12939-019-0933-2. 
15. Cai F, Giles J, O'Keefe P, Wang D. The elderly and old age support in rural China: Challenges and prospects. Directions in development. Washington DC: World Bank Publications; 2012. Available from: http://documents. worldbank.org/curated/en/769231468215685476/The-elderly-and-old-agesupport-in-rural-China-challenges-and-prospects Accessed 1 Jun 2020.

16. The National Bureau of Statistics of China. Statistical bulletin of the people's Republic of China on national economic and social development 2017. http://www.stats.gov.cn/tjsj/zxfb/201802/t20180228_1585631.html Accessed 1 Jun 2020.

17. Lan $\mathrm{X}$, et al. Assessing the effects of the percentage of chronic disease in households on health payment-induced poverty in Shaanxi Province, China. BMC Health Servs Res. 2018;18(1):871. https://doi.org/10.1186/s12913-0183698-1.

18. Wehby GL, Domingue BW, Wolinsky FD. Genetic risks for chronic conditions: Implications for long-term wellbeing. J Gerontol Series A. 2018;73(4):477-83. Available from: https://academic.oup.com/biomedgerontology/article/73/4/4 77/4079819 Accessed 1 Jun 2020. https://doi.org/10.1093/gerona/glx154.

19. Kutzin J. Health financing for universal coverage and health system performance: concepts and implications for policy. Bull World Health Organ. 2013;91(8):602-11. https://doi.org/10.2471/BLT.12.113985.

20. The National Bureau of Statistics of China. Interim Statistical Monitoring Report on the China Women's Development Programme (2011-2020). http://www.stats.gov.cn/tjsj/zxfb/201611/t20161103_1423701.html Accessed 1 Jun 2020.

21. Hu J, Mossialos E. Pharmaceutical pricing and reimbursement in China: when the whole is less than the sum of its parts. Health Policy. 2016 Apr 12; 120(5):519-34. https://doi.org/10.1016/j.healthpol.2016.03.014.

22. Xu K, Evans DB, Kawabata K, Zeramdini R, Klavus J, Murray CJ. Household catastrophic health expenditure: A multicountry analysis. The Lancet. 2003; 362(9378):111-7. https://doi.org/10.1016/S0140-6736(03)13861-5.

23. Song $Y$, Song $Z$. The promoting effect and its mechanism of health insurance on the migrants' consumption. Popul Econ. 2018;(3):115-26.

24. He H, Nolen PJ. The effect of health insurance reform: Evidence from China. China Econ Rev. 2019;53:168-ss. https://doi.org/10.1016/j.chieco.2018.08.013.

25. Garg S, Chowdhury S, Sundararaman T. Utilisation and financial protection for hospital care under publicly funded health insurance in three states in southern India. BMC Health Serv Res. 2019 Dec 27;19(1):1004. https://doi. org/10.1186/s12913-019-4849-8.

26. Tang D, Gao X, Coyte PC. The effects of compulsory health insurance on birth outcomes: evidence from China's UEBMI scheme. BMC Health Serv Res. 2019 Nov 01;19(1):779. https://doi.org/10.1186/s12913-019-4657-1.

27. Meng Y, Han J, Qin S. The impact of health insurance policy on the health of the senior floating population-evidence from China. Int J Environ Res Public Health. 2018 Oct 01;15(10):2159. https://doi.org/10.3390/ ijerph15102159

28. Wooldridge JM. Further results on instrumental variables estimation of average treatment effects in the correlated random coefficient model. Econ Lett. 2003;79(2):185-91. https://doi.org/10.1016/S0165-1765(02)00318-X.

29. Lewbel A. Endogenous selection or treatment model estimation. J Econom. 2007;41(2):777-806. https://doi.org/10.1016/j.jeconom.2006.11.004.

30. Wagstaff A, Floers G, Hsu J, Smitz M, Chepynoga K, Buisman LR, et al. Progress on catastrophic health spending in 133 countries: A retrospective observational study. Lancet Glob Health. 2018;6(2):169-79. https://doi.org/ 10.1016/S2214-109X(17)30429-1.

31. Li Y, Wu Q, Legge D, Hao Y, Gao L, Ning N, et al. Factors affecting catastrophic health expenditure and impoverishment from medical expenses in China: policy implications of universal health insurance. Bull World Health Organ. 2012 Sep 01;90(9):664-71. https://doi.org/10.2471/BLT. 12.102178 .

32. Yardim MS, Cilingiroglu N, Yardim N. Catastrophic health expenditure and impoverishment in Turkey. Health Policy. 2009;94(1):26-33. https://doi.org/ 10.1016/j.healthpol.2009.08.006

33. Koch KJ, Pedraza CC, Schmid A. Out-of-pocket expenditure and financial protection in the Chilean health care system - a systematic review. Health Policy. 2017;121(5):481-4. https://doi.org/10.1016/j.healthpol.2017.02.013.

34. Chen Y, Shi J, Zhuang CC. Income-dependent impacts of health insurance on medical expenditures: theory and evidence from China. China Econ Rev. 2019 Feb;53:290-310. https://doi.org/10.1016/..chieco.2018.10.002.

35. Shi F, Zhu W, Zhang WP, Liu HM. Trends in inpatient utilization and expenditure for the new cooperative medical scheme in a city. J Med Forum. 2011;32(12):107-9.
36. Chandoevwit W, Phatchana P. Inpatient care expenditure of the elderly with chronic diseases who use public health insurance: Disparity in their last year of life. Soc Sci Med. 2018;207:64-70. https://doi.org/10.1016/j.socscimed. 2018.04.042.

37. Bhojani U, Thriveni BS, Devadasan R, Munegowda CM, Devadasan N, Kplsteren P, et al. Out-of-pocket healthcare payments on chronic conditions impoverish urban poor in Bangalore, India. BMC Public Health. 2012;12:990. https://doi.org/10.1186/1471-2458-12-990.

38. Mwangi J, Kulane A, Hoi LV. Chronic diseases among the elderly in a rural Vietnam: prevalence, associated socio-demographic factors and healthcare expenditures. Int J Equity Health. 2015;14(1). https://doi.org/10.1186/s12939015-0266-8

39. Garcia JL, Ruiz SP. Development of capabilities from the innovation of the perspective of poverty and disability. J Innovation Knowledge. 2017;2(2):7486. https://doi.org/10.1016/j.jik.2017.07.002.

40. Pinilla-Roncancio M. The reality of disability: Multidimensional poverty of people with disability and their families in Latin America. Disabil Health J. 2018;11(3). https://doi.org/10.1016/j.dhjo.2017.12.007.

41. Bayudan-Dacuycuy C, Lim JA. Family size, household shocks and chronic and transient poverty in the Philippines. J Asian Econ. 2013;29:101-12. https://doi.org/10.1016/j.asieco.2013.10.001.

\section{Publisher's Note}

Springer Nature remains neutral with regard to jurisdictional claims in published maps and institutional affiliations.
Ready to submit your research? Choose BMC and benefit from:

- fast, convenient online submission

- thorough peer review by experienced researchers in your field

- rapid publication on acceptance

- support for research data, including large and complex data types

- gold Open Access which fosters wider collaboration and increased citations

- maximum visibility for your research: over $100 \mathrm{M}$ website views per year

At BMC, research is always in progress.

Learn more biomedcentral.com/submissions 